University of Wollongong

Research Online

Faculty of Engineering and Information

Faculty of Engineering and Information

Sciences - Papers: Part A

Sciences

2004

Placement and penetration of distributed generation under standard market design

Ashish Agalgaonkar

University of Wollongong, ashish@uow.edu.au

S V. Kulkarni

Indian Institute of Technology - Bombay

S A. Khaparde

Indian Institute of Technology - Bombay

S A. Soman

Indian Institute of Technology - Bombay

Follow this and additional works at: https://ro.uow.edu.au/eispapers

Part of the Engineering Commons, and the Science and Technology Studies Commons

Research Online is the open access institutional repository for the University of Wollongong. For further information contact the UOW Library: research-pubs@uow.edu.au 


\title{
Placement and penetration of distributed generation under standard market design
}

\author{
Abstract \\ Distributed Generation (DG) can help in reducing the cost of electricity to the costumer, relieve network \\ congestion and provide environmentally friendly energy close to load centers. Its capacity is also scalable \\ and it provides voltage support at distribution level. Hence, DG placement and penetration level is an \\ important problem for both the utility and DG owner. The cost of electricity as a commodity depends upon \\ market model. The restructured power markets are slowly maturing with standardizations like Standard \\ Market Design (SMD). The key feature of SMD is the Locational Marginal Pricing (LMP) scheme. This \\ paper examines placement and penetration level of the DGs under the SMD framework. The proposed \\ approach is illustrated by case studies on MATPOWER 30 bus and IEEE 118 bus systems.
}

\section{Keywords}

standard, under, design, generation, market, distributed, penetration, placement

Disciplines

Engineering | Science and Technology Studies

\section{Publication Details}

Agalgaonkar, A. P., Kulkarni, S. V., Khaparde, S. A. \& Soman, S. A. (2004). Placement and penetration of distributed generation under standard market design. International Journal of Emerging Electric Power Systems, 1 (1), 1-16. 


\title{
Placement and Penetration of Distributed Generation under Standard Market Design
}

\author{
A. P. Agalgaonkar, S. V. Kulkarni, S. A. Khaparde, and S. A. Soman
}

\begin{abstract}
Distributed Generation (DG) can help in reducing the cost of electricity to the costumer, relieve network congestion and provide environmentally friendly energy close to load centers. Its capacity is also scalable and it provides voltage support at distribution level. Hence, DG placement and penetration level is an important problem for both the utility and DG owner. The cost of electricity as a commodity depends upon market model. The restructured power markets are slowly maturing with standardizations like Standard Market Design (SMD). The key feature of SMD is the Locational Marginal Pricing (LMP) scheme. This paper examines placement and penetration level of the DGs under the SMD framework. The proposed approach is illustrated by case studies on MATPOWER 30 bus and IEEE 118 bus systems.
\end{abstract}

KEYWORDS: Distributed Generation, Locational Marginal Pricing, Standard Market Design, Penetration level

Author Notes: The authors gratefully acknowledge the financial support from Ministry of Human Resource and Development (MHRD), India for the project titled Planning Studies for Distributed Generation (as per sanction order no. F.26-4/2002.TS.V). 
Agalgaonkar et al.: Placement and Penetration of Distributed Generation under Standar

\section{Introduction}

The restructured power markets have evolved around scale of economy making the smaller generating units viable and feasible. Major countries have pumped huge investments in the dispersed generations for the simple reasons of relief on building new transmission systems, effective loss reduction and increased reliability. They also offer at least partial solutions to congestion problems. In developing countries where generation is insufficient as compared to demand, the Independent Power Producers (IPP) and Captive Power Plants (CPP) are encouraged as a policy matter, which further facilitates the DG option. The application of small generators such as diesel, I.C. engine, small gas turbines, fuel cells and photovoltaic cells, scattered throughout the power system will cope up with the growing demand for electricity in certain areas and render certain activities self-sufficient in terms of power production and achieving energy savings.

There are number of important issues to be considered while carrying out studies related to the planning and operational aspects of a DG set. The planning studies include penetration level and placement evaluation, which are influenced by the type of DG. The connection to grid generally should be the preferred option, which allows injection of power into grid making the DG scheme more viable. The basic objective of [Celli and Pilo, 2002] is to minimize the total cost of operation including the fixed and variable costs. The costs of buying energy from transmission system and from DG units should be considered so as to have a proper assessment of the penetration level of a DG in distribution system. DG will influence the optimal dispatch of the system. The limitation of this approach is that it does not consider the optimal power flow of the system after the inclusion of DG. The method for optimal placement of DG using Genetic Algorithm (GA) and its penetration level assessment by Optimal Power Flow (OPF) has been proposed by [Kulkarni et al., 2003]. The objectives include reduction in T\&D losses and improvement of voltage profile of the system, with due consideration of fixed and variable costs. [Brown et al., 2001] presents a network capacity expansion algorithm capable of deferring T\&D expansion by optimally siting DG units at new or existing substations. It uses a successive elimination algorithm that begins with all expansion options (new lines, upgraded lines, new substations, expanded substations and DG), and then successively eliminates the least costeffective alternatives until any further elimination violates the system constraints. The algorithm is then applied to a test system representing a US urban subtransmission system. Viability of DG option is checked for specific new and existing substations where large transmission and / or substation projects can be deferred.

The optimization model for minimization of losses through constrained power flows and optimal siting of DGs in a multi-bus distribution network is 
presented in [Davidson and Ijumba, 2002]. The main objective is to minimize the line losses subject to meeting generation revenue, transmission constraints and consumer demand. Optimal placement of DG will reduce the total cost of operation considerably, which will help system planners to defer the reinforcement of a system done in the conventional way, and improve the performance of existing system with respect to voltage profile and system losses. This is because of the fact that DG located near the load will inject active power (current) to satisfy the demand, which will reduce the power intake from distribution substation [Khattam and Salama, 2002]. Some analytical methods, which use closed form equations, are formulated in [Bhowmik et al., 2003] to predict allowable distributed generation resources on a radial distribution feeder before voltage harmonic limits are exceeded. The final result is the determination of allowable penetration levels of distributed generation resources for a range of distribution feeders. The study is useful for determination of viable DG capacity in a typical distribution system. The selection of particular type of distributed resource based upon some specific system constraints, have significant impact over the siting of DG [Alvarado, 2001]. Some aspects of market regulations regarding their impact on future developments of DG are dealt with in [Ackermann et al., 2000].

In this paper, we consider the DG placement and penetration level assessment problem in the SMD framework. The cost of the electricity available from the grid is given by the nodal LMP while the cost of electricity of the DG depends upon its type, capacity, etc. The first objective is to locate DG at economically viable locations (siting problem). The penetration level of the DG has to be computed incrementally by OPF. Capacity addition by DG will affect the economic dispatch and hence LMP costs. Hence, the problem becomes nonlinear and iterative. The case studies for MATPOWER 30 bus and IEEE 118 bus system are presented. They consider the economically viable locations and penetration level assessment for various types of DGs like reciprocating engine, mini gas turbine, fuel cell, etc. The paper is organized as follows. Section-2 describes the role of DG in the deregulated environment. SMD market and LMP calculation are discussed in section 3. DG planning under SMD is considered in section-4. Results are presented in section 5. Section 6 concludes the paper.

\section{Distributed Generation in Deregulated Environment}

In addition to meeting future energy needs, DG will also have significant importance in a deregulated environment. It can provide independence and flexibility to the consumers in planning and developing the installation as per the criticality of the load. It can minimize the investment made over T\&D 
Agalgaonkar et al.: Placement and Penetration of Distributed Generation under Standar

infrastructure by locating it near the load. It has potential to serve as an ancillary service.

Many new DG models are commercialized in United States and Europe. The liberalization of wholesale and retail electric markets is giving rise to customer choice and new offerings by unregulated energy retailers [Engel, 2000]. Due to the continuous improvements in DG technologies, it is possible to provide cost effective electricity to the customers. In wholesale power markets, customer owned DGs can respond to the extreme price swings so as to reduce the volatility in prices. Utility operated DG can defer Transmission and Distribution (T\&D) upgrades and hence it can be considered as one of most viable options in the planning process. During peak hours and emergencies, a part of the total load can be transferred to an isolated generator, relieving the utility's burden to some extent. Furthermore, the parallel operation of DG with the utility is much more flexible than that of the stand-alone system [Shahidehpour, 2002]. The small size of DG is beneficial from the reliability point of view as its failure does not have a major impact on the power system.

In the year 2001, it was observed that the total capacity of diesel powered emergency standby generators in California was around $30 \mathrm{GW}$ [Lively, 2001], but very few of them were operating in parallel with the interconnected power system. The various issues related to the penetration level assessment of these generators can be resolved by treating electricity as if it were a fungible commodity. In that situation, electricity can be bought and sold on a true spot basis in contrast to being purchased on a contract or futures market.

DG is best suited for demand side management programs. It can be viewed as an ancillary service for voltage control. It has energy attributes (such as the ability to recover waste heat) that distinguish it from central generation. Combined Heat and Power (CHP) systems can dramatically change site economics. These systems can compete with utility-supplied power in most service areas. DG can be used to attain higher levels of end-user reliability than those possible from central generating stations.

In competitive electricity markets, DG can compete with the centralized power generation and hence market regulations should ensure that there should be standard operational practices and reliability requirements so as to have fair competitive environment for DG. Various electricity market models like pool model (UK and Nordic pool), SMD (USA) are in operation in different parts of the world. Since the cost of electricity from the grid is dependent upon the market model, the model will influence the DG planning. SMD model is gaining significance because it can consider the locational pricing. As will be shown later in this paper, locational pricing model is suitable for DG placement problem. SMD is reviewed in the next section. 


\section{Standard Market Design}

The difficulties faced by some of the restructured markets made it necessary to modify and set some standards for market design. Federal Electric Regulatory Commission (FERC) proposed SMD for seamless operation between the regions. This will reduce trade barriers, bring compatibility among the softwares and hence increase competition among the various players by reducing price. SMD has been implemented in most power markets of USA [Ma et al., 2003]. SMD uses LMP for energy settlement, the multi-settlement markets and ancillary services. There exist other issues also like market monitoring and mitigation, demand response program, etc. which are unique to SMD.

LMP provides market participants a clear and accurate signal of the price of electricity at every location on the grid. These prices, in turn, reveal the value of locating new generation or of upgrading transmission systems. Under SMD, the term 'multi-settlement market' implies that the energy market consists of dayahead and real time markets, each producing its own separate and unique financial settlements. The day-ahead market produces generation and load schedules one day ahead before operating day. The real time market reconciles any differences between the amounts of scheduled day ahead and real time conditions. The DGs can participate in the real time market.

Ancillary services are defined as services provided in addition to real power generation by the electric utilities, and services that must be provided separately under a deregulated environment, which include reactive support for voltage control, automatic generation control, operating and spinning reserves so as to cope up with planned and forced outages, power system stabilizer for system stability, etc. Market power refers to the ability of some of the consumers to manipulate the market prices. Market power may result from transmission congestion. Market power monitoring program identifies market design flaws and recommends mitigation rules.

In this work, we assume that the market operates under the SMD framework. Hence, the knowledge of LMP at every node is used to take a decision for the placement of a DG.

\subsection{Locational Marginal Pricing}

In the energy marketplace, utility customer transactions are usually based on the hourly spot price. It may be on half hourly or 15 minutes interval basis. The hourly spot price is determined by the demand at that hour and the hourly varying costs and capabilities of the generation, transmission and distribution systems. The hourly spot price is defined in terms of marginal costs subject to recovery of operating cost and capital investment [Schweppe et al., 1988]. This includes generation marginal fuel and maintenance plus generation and network quality of supply plus generation and network revenue reconciliation plus network marginal 
losses. Quality of supply components are like reliability surcharges. They arise when generation or network capacity limits are being approached.

The marginal fuel and maintenance cost comprises system lambda, $\lambda(t)$. It is defined as the partial derivative of generation fuel and maintenance cost with respect to demand at hour $t$. It can be calculated from unit commitment generation dispatch logics. The effect of various transactions among the interconnected utilities is included in it.

LMPs reflect the marginal cost of serving the last megawatt of demand at a specific location on the electrical network (node) assuming optimally dispatched generation. This includes generation marginal cost, transmission congestion cost and marginal transmission losses. In economic dispatch, the last megawatt increase in load is normally served by the least expensive generating unit in the system, however, in case of congestion this may not be the right strategy and additional congestion cost needs to be calculated at a node as the difference between the LMPs with and without the congestion.

The determination of LMPs is similar, but not identical, in the day-ahead and real-time markets. Day-ahead LMPs are output from the day-ahead market clearing process. Generation, demand, external contracts, and increment and decrement positions that clear in the day-ahead market settle at prices determined by day-ahead LMPs. The real-time market balances supply and demand as the system operates. Real-time LMPs are based on current power system operating data. Deviations between day-ahead and actual real-time positions settle at prices determined by real-time LMPs.

\subsection{OPF Formulation}

The heart of the above algorithm is the OPF program. The OPF schedules the MW generations throughout the system to minimize cost of generation or social welfare cost. In particular we consider the objective function to be the total cost of real power generation. These costs may be defined as polynomials or as piecewise-linear functions of generator output. The problem is formulated as follows [Zimmerman and Gan, 1997]:

$$
\min _{p_{g}} \sum f_{i}\left(P_{g i}\right)
$$

$$
\begin{aligned}
& \text { Such that, } \\
& P_{g i}-P_{L i}-P(V, \theta)=0 \text { (active power balance equations) } \\
& \begin{array}{c}
Q_{g i}-Q_{L i}-Q(V, \theta)=0 \text { (reactive power balance equations) } \\
S_{i j} \leq S_{i j}^{\max } \text { (line flow limits) } \\
V_{i}^{\min } \leq V_{i} \leq V_{i}^{\max } \text { (bus voltage limits) }
\end{array}
\end{aligned}
$$




$$
\begin{gathered}
P_{g i}^{\min } \leq P_{g i} \leq P_{g i}^{\max }(\text { active power generation limit) } \\
Q_{g i}^{\min } \leq Q_{g i} \leq Q_{g i}^{\max }(\text { reactive power generation limit) }
\end{gathered}
$$

Here $f_{i}$ is the cost of active power generation for generator $i$ at a given dispatch point and it is assumed to be a polynomial or piecewise-linear function. The lagrangian multiplier corresponding to the power balance equation at a node provides the sensitivity of the cost or objective function with respect to the nodal injection. If change in injection is caused by the corresponding change in load, then, it is evident that the nodal lagrangian multipliers also correspond to the LMP. The nodal price signal is an indicator for the additional reinforcement required in terms of generation or transmission and distribution at each node in the system. The realistic LMP based DG planning approach is proposed in the next section.

\section{DG Planning under SMD}

The problems related to the placement and penetration level assessment of a DG can be formulated on the basis of nodal LMPs. The optimal placement of a DG requires finding the strategic locations for it according to the customer level cost of energy. Penetration level of the DG is the percentage of total demand supplied economically by it. The problem statement is to find the economically viable locations and corresponding MWs for various types of DGs like reciprocating engine, mini gas turbine, fuel cell, etc.

The placement of DG can be considered on the basis of nodal LMPs. To start with, the base case OPF of a system is solved. LMPs at system nodes correspond to the price of a unit power received at the node. The node with the highest LMP is a clear candidate for locating the DG since it will yield highest returns. In the formulation, the DG is considered as a negative load and it is assumed that it will be paid at the rate of LMP. The algorithm is as follows:

Step 0: Initialize the installed DG at each node for each DG type to be equal to zero, iteration $=0$

Step 1: Run base case security constrained OPF to minimize the total cost of generation or maximize the social benefit function. Consequently, all generation available for scheduling is scheduled optimally.

Step 2: Find the node with the highest LMP.

Step 3: If the maximum LMP is lower than minimum viable DG cost (\$ / MWh) option, terminate the algorithm. Else proceed to step4. 
Agalgaonkar et al.: Placement and Penetration of Distributed Generation under Standar

Step 4: Choose suitable (acceptable) type of DG and locate it at the node with maximum LMP. Initially selection of DG type may reflect preference of the planner. Also once, a particular type of DG is selected at a given location, other DG options at that site may be inhibited.

Step 5: Increment the installed DG at the max LMP node either by a small value, e.g., $1 \mathrm{MW}$ or a value based on the judgment of planner. Step 6: Iteration +1 , run new OPF to obtain new set of LMPs and go to step 2 .

The process terminates when the cost of energy ( $\$$ / MWh) supplied by cheapest available DG is higher than the maximum LMP (\$ / MWh) in the system. At this point, no incremental addition of DG in the system is economically viable. It should be noted that in step-5, the emphasis is placed on incremental addition of the DG capacity. A simple way to understand this requirement is based on the reasoning that DG effectively reduces the net load at a given bus. This model is perfectly valid if DG is only used to supply local load at a bus. As the net load on the system reduces, so do the losses and the net generation. By considering the monotonically increasing behavior of generation cost curve, it is evident that reduction in load lowers both the marginal and total costs in the system. Hence, LMPs tend to reduce with incremental addition in DG. Hence, at any given step, one cannot install large DG MW at a given node. Conceptually, the cutoff point occurs when the DG costs equal the LMP at that node (Figure 1). In this figure, it is assumed that $\$ / \mathrm{MWh}$ of DG is a constant independent of MW generation. Other type of cost curves for DG can also be modeled. They will shift the point of intersection.

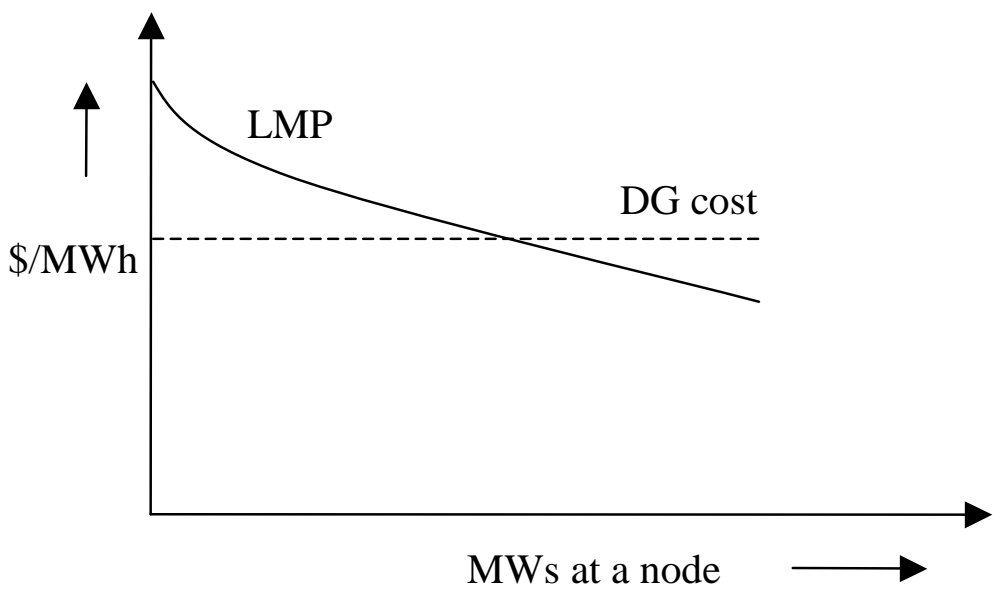

Figure 1 LMPs as a function of a net load at a node 
The proposed algorithm models the behavior illustrated in Figure 1. Also, it should be realized that the maximum LMP node may not be static. Even an incremental addition of DG can alter the maximum LMP node at the subsequent iteration. Thus, at successive iteration of the proposed algorithm, the DG placement may change. However, the algorithm accumulates incremental DG installments for each location because it is possible that in a subsequent iteration the same site may be re-visited for DG placement. An alternative strategy could be to follow the curve in figure 1 at a specified node (e.g., first maximum LMP node) until no further capacity addition is possible at that node. Only then, alternative node selection is done. However, our experience suggests the first strategy to be more useful. It is evident from the above discussions that DG placement and capacity addition (penetration level evaluation) is a coupled problem. Even an incremental addition of generation at a given node can alter the maximum LMP node at the next iteration and hence the DG placement and next incremental DG capacity addition.

\section{Results}

In this section, we present case studies for MATPOWER 30 and IEEE 118 bus system. The nodal LMP at each bus is calculated by using the standard OPF formulation of the MATPOWER package. The costs per unit value are available for the capacity and type of DG in the literature [Willis and Scott, 2000] or they should be calculated for particular sites under consideration. The penetration level can be defined on the base case and peak case. For the peak case, the capacity will be higher than the base case. Similarly, when per unit cost of the DGs are compared, one can consider the peaking or base case values. In this work, per unit cost for peaking values are considered. The DG viability increases if the contingency is considered since the LMPs increase under contingency. A rigorous definition of LMP requires the use of security constrained OPF. However, in this work, we associate LMPs with the Lagrangian multipliers of the OPF and compute separate set of LMPs under contingency. These LMPs are compared with the customer level cost of various types of DGs. The peaking cost of energy at customer level due to various types of DGs along with the DG lifetime and its initial cost are tabulated below. The cost of energy is computed using a discount factor of $11.1 \%$. 
Agalgaonkar et al.: Placement and Penetration of Distributed Generation under Standar

Table 1 Cost of energy with various types of DGs [Willis and Scott, 2000]

\begin{tabular}{|c|c|c|c|c|c|}
\hline DG type & $\begin{array}{c}\text { Initial } \\
\text { cost } \\
(\$ / \mathrm{kW})\end{array}$ & $\begin{array}{c}\% \\
\text { efficiency }\end{array}$ & $\begin{array}{c}\% \\
\text { availability }\end{array}$ & $\begin{array}{c}\text { Life in } \\
\text { years }\end{array}$ & $\begin{array}{c}\text { Cost of } \\
\text { energy* at } \\
\text { customer } \\
\text { level } \\
(\$ / \mathrm{MWh})\end{array}$ \\
\hline Reciprocating & 433 & 40 & 97 & 20 & 110 \\
\hline Mini gas turbine & 420 & 29 & 97 & 20 & 120 \\
\hline Fuel cell & 750 & 42 & 97 & 10 & 131 \\
\hline
\end{tabular}

* peaking

\subsection{Placement and penetration of DG in MATPOWER 30 bus system}

For MATPOWER 30 bus system the cost function for all the six generators is in the form of quadratic equation as shown in the table 2, where $P_{g}$ is in MW. The results are tabulated in table 3 . The results of placement and penetration of DG are shown graphically in figure 2, whereas the impact of DG penetration on system LMP (maximum LMP in the system) is shown in figure 3.

Table 2 Cost functions of the generators

\begin{tabular}{|c|c|c|c|}
\hline Bus Number & Cost function & Bus Number & Cost function \\
\hline 1 & $P_{g 1}^{2}+59 P_{g 1}$ & 22 & $P_{g 4}^{2}+57 P_{g 4}$ \\
\hline 2 & $P_{g 2}^{2}+60 P_{g 2}$ & 23 & $P_{g 5}^{2}+62 P_{g 5}$ \\
\hline 13 & $P_{g 3}^{2}+58 P_{g 3}$ & 27 & $P_{g 6}^{2}+58 P_{g 6}$ \\
\hline
\end{tabular}

Referring to the table 1, the lowest customer level cost of DG for peaking condition is $\$ 110 / \mathrm{MWh}$ and accordingly the placement process will terminate as soon as the highest system LMP is less than $\$ 110 / \mathrm{MWh}$. As the highest system LMP of a MATPOWER 30 bus system is larger than that of the customer level cost of DG, the planning process starts with the costlier resource and after exhausting its capacity, the next type of DG is considered. From the table 3 , it is seen that the maximum allowable capacity for fuel cells, mini gas turbine and reciprocating engine type DGs is $1.5 \mathrm{MW}, 15.5 \mathrm{MW}$ and $28 \mathrm{MW}$ respectively. The location, type and MW requirement of DG is illustrated in figure 2. Overall, it is observed that the total DG penetration at peaking condition is around $24 \%$ (45 MW) of the total load of 189.2 MW. As the DG penetration increases there will be a load relief for the system and hence the system LMPs go down as shown in figure 3. 
International Journal of Emerging Electric Power Systems, Vol. 1 [2004], Iss. 1, Art. 1004

Table 3 Results for siting and sizing of DG (MATPOWER 30 bus system)

\begin{tabular}{|c|c|c|c|c|c|c|c|}
\hline \multirow[t]{2}{*}{$\begin{array}{l}\text { Iteratio } \\
\text { n count }\end{array}$} & \multirow[t]{2}{*}{$\begin{array}{c}\text { Location } \\
\text { of DG } \\
\text { (Bus No.) }\end{array}$} & \multirow{2}{*}{$\begin{array}{l}\text { Total } \\
\text { DG } \\
\text { capacity } \\
(\mathrm{MW})\end{array}$} & \multirow[t]{2}{*}{$\begin{array}{l}\text { DG } \\
\text { type }\end{array}$} & \multicolumn{2}{|c|}{$\begin{array}{c}\text { Load before } \\
\text { DG } \\
\text { placement }\end{array}$} & \multirow{2}{*}{$\begin{array}{l}\text { Highest } \\
\text { system } \\
\text { LMP } \\
\text { (\$/MWh) }\end{array}$} & \multirow{2}{*}{$\begin{array}{l}\text { Node } \\
\text { with } \\
\text { highest } \\
\text { system } \\
\text { LMP }\end{array}$} \\
\hline & & & & $\mathrm{P}_{\mathrm{L}}$ & $\mathrm{Q}_{\mathrm{L}}$ & & \\
\hline 1 & No DG & Nil & -- & - & - & 180.29 & 8 \\
\hline 2 & 8 & 1.5 & Fuel Cell & 30 & 30 & 127.68 & 19 \\
\hline 3 & 19 & 1.5 & M.G.T.\# & 9.5 & 3.4 & 126.79 & 30 \\
\hline 4 & 30 & 1 & M.G.T. & 10.6 & 1.9 & 126.10 & 19 \\
\hline 5 & 19 & 5 & M.G.T. & 8 & 2.86 & 124.09 & 30 \\
\hline 6 & 30 & 5 & M.G.T. & 9.6 & 1.72 & 120.99 & 19 \\
\hline 7 & 19 & 3 & M.G.T. & 3.0 & 1.07 & 119.65 & 17 \\
\hline 8 & 17 & 5 & R.E.* & 9.0 & 5.8 & 117.51 & 20 \\
\hline 9 & 20 & 2 & R.E. & 2.2 & 0.7 & 116.78 & 7 \\
\hline 10 & 7 & 5 & R.E. & 22.8 & 10.9 & 115.05 & 26 \\
\hline 11 & 26 & 3 & R.E. & 3.5 & 2.3 & 113.97 & 14 \\
\hline 12 & 14 & 1 & R.E. & 6.2 & 1.6 & 113.53 & 17 \\
\hline 13 & 17 & 2 & R.E. & 4.0 & 2.57 & 112.70 & 14 \\
\hline 14 & 14 & 3 & R.E. & 5.2 & 1.34 & 111.62 & 17 \\
\hline 15 & 17 & 2 & R.E. & 2 & 1.28 & 110.87 & 7 \\
\hline 16 & 7 & 5 & R.E. & 17.8 & 8.5 & 109.02 & 20 \\
\hline
\end{tabular}

\# Mini Gas Turbine * Reciprocating Engine

DOI: $10.2202 / 1553-779 X .1003$ 
Agalgaonkar et al.: Placement and Penetration of Distributed Generation under Standar

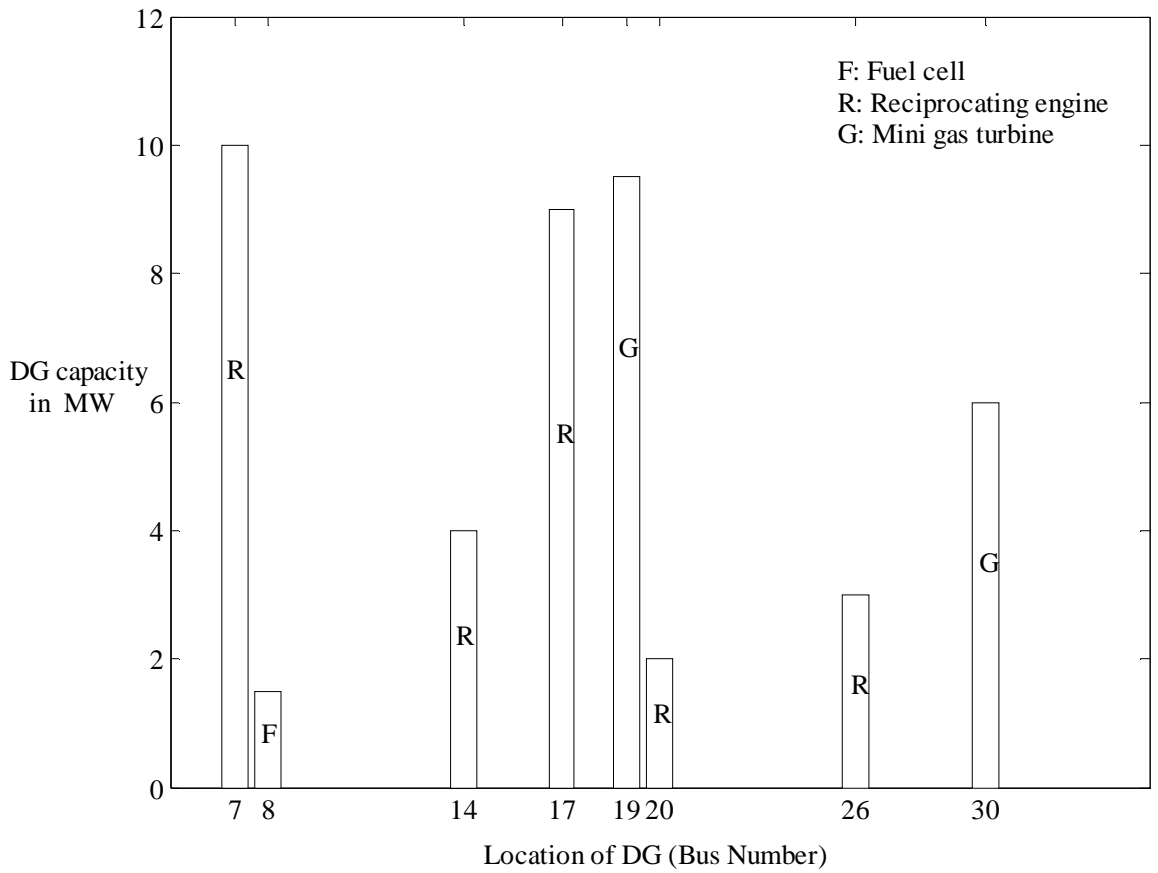

Figure 2 Placement and penetration of DG in MATPOWER 30 bus system

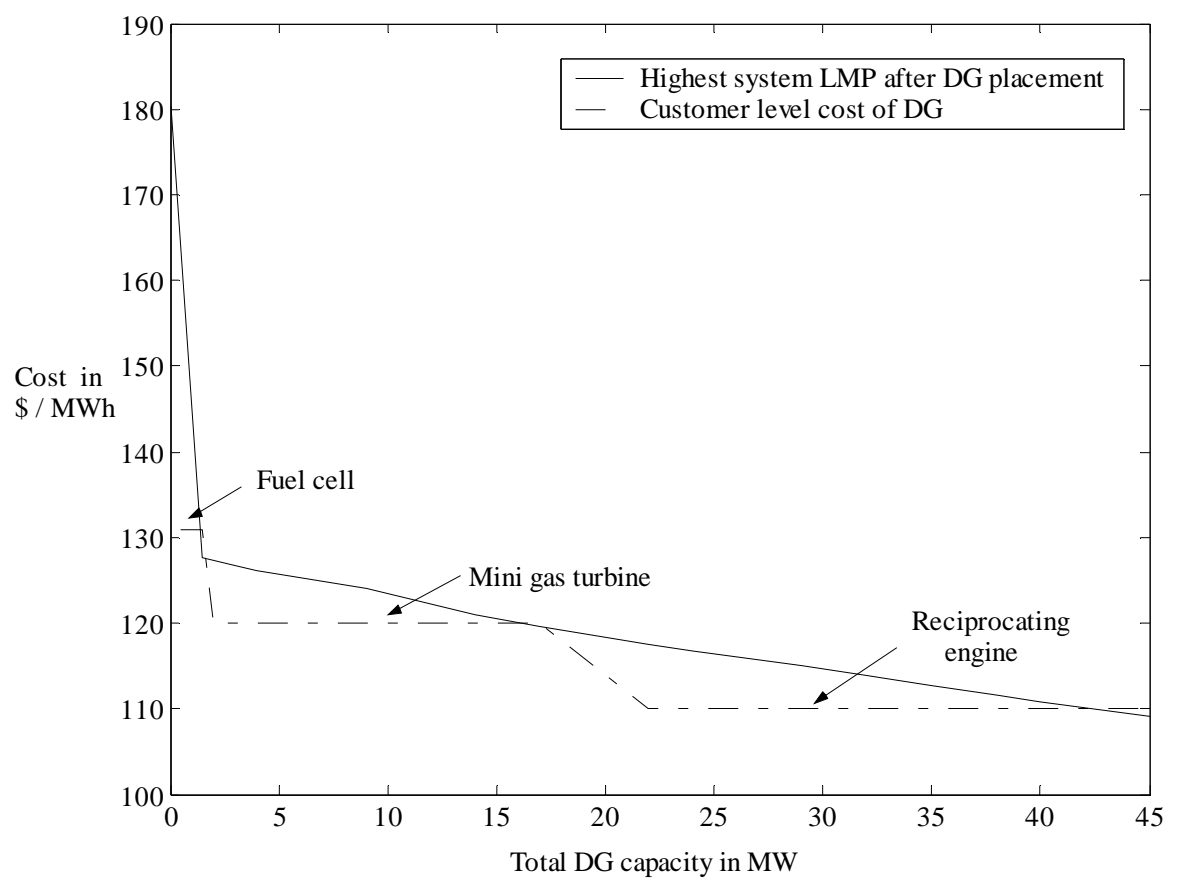

Figure 3 Impact of DG penetration on system LMP (MATPOWER 30 bus) 


\subsection{Placement and penetration of DG in IEEE 118 bus system}

MATPOWER 30 bus system modeled quadratic cost curves for generators. In IEEE 118 bus system, the cost function for some of the generators is considered to be linear so as to reduce the computational burden of the solver. The change in system LMPs with the inclusion of DG is as shown in Table 4 and the same is plotted in figure 5. As the base case LMPs (without inclusion of DG) are on higher side, the costlier DGs like fuel cell also become viable. In this case, it is observed that the DG penetration at peaking condition is around 9\% (372 MW) of the total load of $4255 \mathrm{MW}$.

Table 4 Results for siting and sizing of DG (IEEE 118 bus system)

\begin{tabular}{|c|c|c|c|c|c|c|c|}
\hline \multirow[t]{2}{*}{$\begin{array}{c}\text { Iteration } \\
\text { count }\end{array}$} & \multirow{2}{*}{$\begin{array}{c}\text { Location } \\
\text { of DG } \\
\text { (Bus } \\
\text { No.) }\end{array}$} & \multirow{2}{*}{$\begin{array}{c}\text { Total } \\
\text { DG } \\
\text { capacity } \\
\text { (MW) }\end{array}$} & \multirow[t]{2}{*}{ DG Type } & \multicolumn{2}{|c|}{$\begin{array}{l}\text { Load } \\
\text { before DG } \\
\text { placement }\end{array}$} & \multirow{2}{*}{$\begin{array}{l}\text { Highest } \\
\text { system } \\
\text { LMP } \\
(\$ / M W h)\end{array}$} & \multirow{2}{*}{$\begin{array}{c}\text { Node } \\
\text { No. } \\
\text { with } \\
\text { highest } \\
\text { system } \\
\text { LMP }\end{array}$} \\
\hline & & & & $\mathrm{P}_{\mathrm{L}}$ & $\mathrm{Q}_{\mathrm{L}}$ & & \\
\hline 1 & No DG & Nil & -- & -- & -- & 163.96 & 52 \\
\hline 2 & 52 & 15 & Fuel Cell & 18 & 5 & 160.68 & 53 \\
\hline 3 & 53 & 20 & Fuel Cell & 23 & 11 & 156.48 & 58 \\
\hline 4 & 58 & 5 & Fuel Cell & 12 & 3 & 155.53 & 52 \\
\hline 5 & 52 & 3 & Fuel Cell & 3 & 0.83 & 154.85 & 58 \\
\hline 6 & 58 & 7 & Fuel Cell & 7 & 1.75 & 153.84 & 45 \\
\hline 7 & 45 & 10 & Fuel Cell & 53 & 22 & 152.41 & 57 \\
\hline 8 & 57 & 12 & Fuel Cell & 12 & 3 & 150.55 & 53 \\
\hline 9 & 53 & 3 & Fuel Cell & 3 & 1.43 & 149.94 & 51 \\
\hline 10 & 51 & 17 & Fuel Cell & 17 & 8 & 147.43 & 45 \\
\hline 11 & 45 & 23 & Fuel Cell & 43 & 17.85 & 144.51 & 59 \\
\hline 12 & 59 & 25 & Fuel Cell & 277 & 113 & 141.06 & 54 \\
\hline 13 & 54 & 25 & Fuel Cell & 113 & 32 & 137.58 & 59 \\
\hline 14 & 59 & 50 & M.G.T. & 252 & 102.8 & 130.74 & 50 \\
\hline 15 & 50 & 17 & M.G.T. & 17 & 4 & 128.42 & 59 \\
\hline 16 & 59 & 25 & M.G.T. & 202 & 82.40 & 125.16 & 48 \\
\hline 17 & 48 & 20 & M.G.T. & 20 & 11 & 122.54 & 59 \\
\hline 18 & 59 & 25 & R.E. & 177 & 72.20 & 119.79 & 45 \\
\hline 19 & 45 & 20 & R.E. & 20 & 8.3 & 117.22 & 54 \\
\hline 20 & 54 & 25 & R.E. & 88 & 24.92 & 113.97 & 59 \\
\hline 21 & 59 & 25 & R.E. & 155 & 63.22 & 110.88 & 47 \\
\hline
\end{tabular}

DOI: 10.2202/1553-779X.1003 
Agalgaonkar et al.: Placement and Penetration of Distributed Generation under Standar

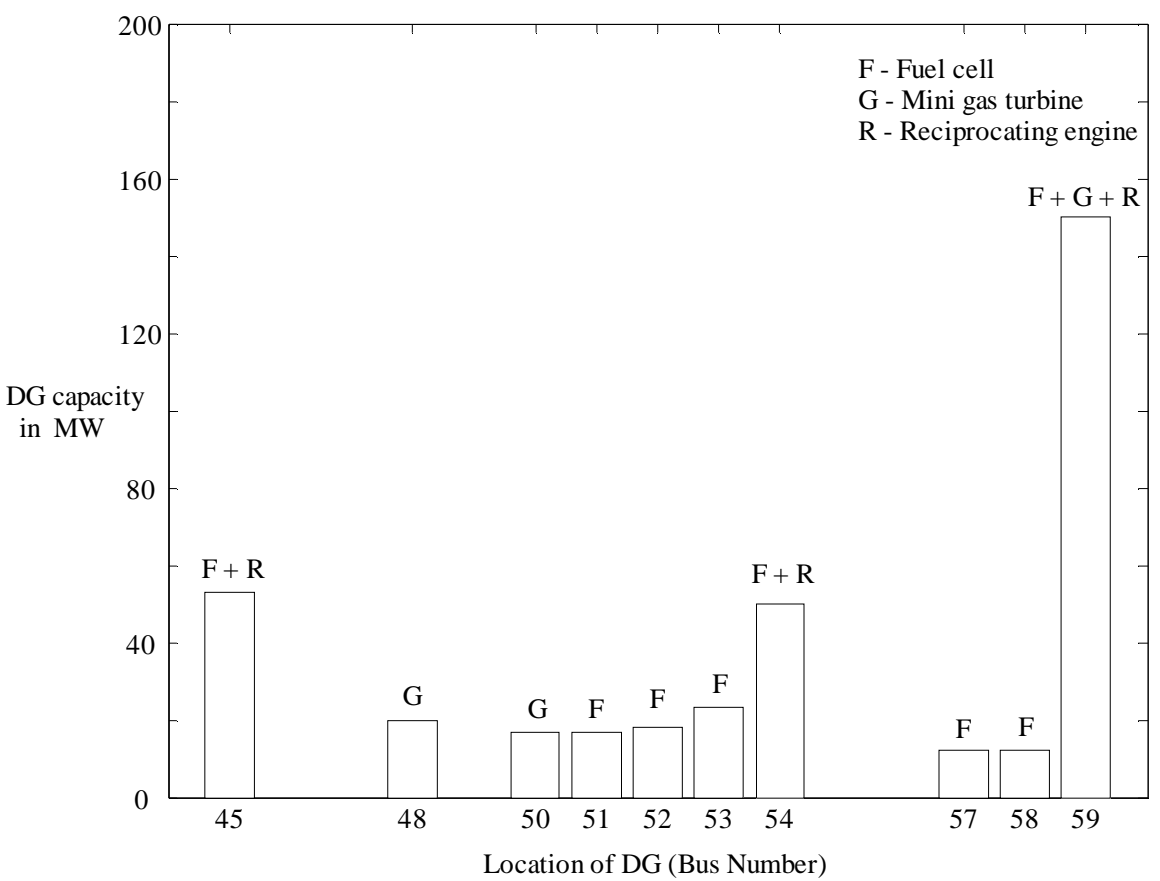

Figure 4 Placement and penetration of DG in IEEE 118 bus system

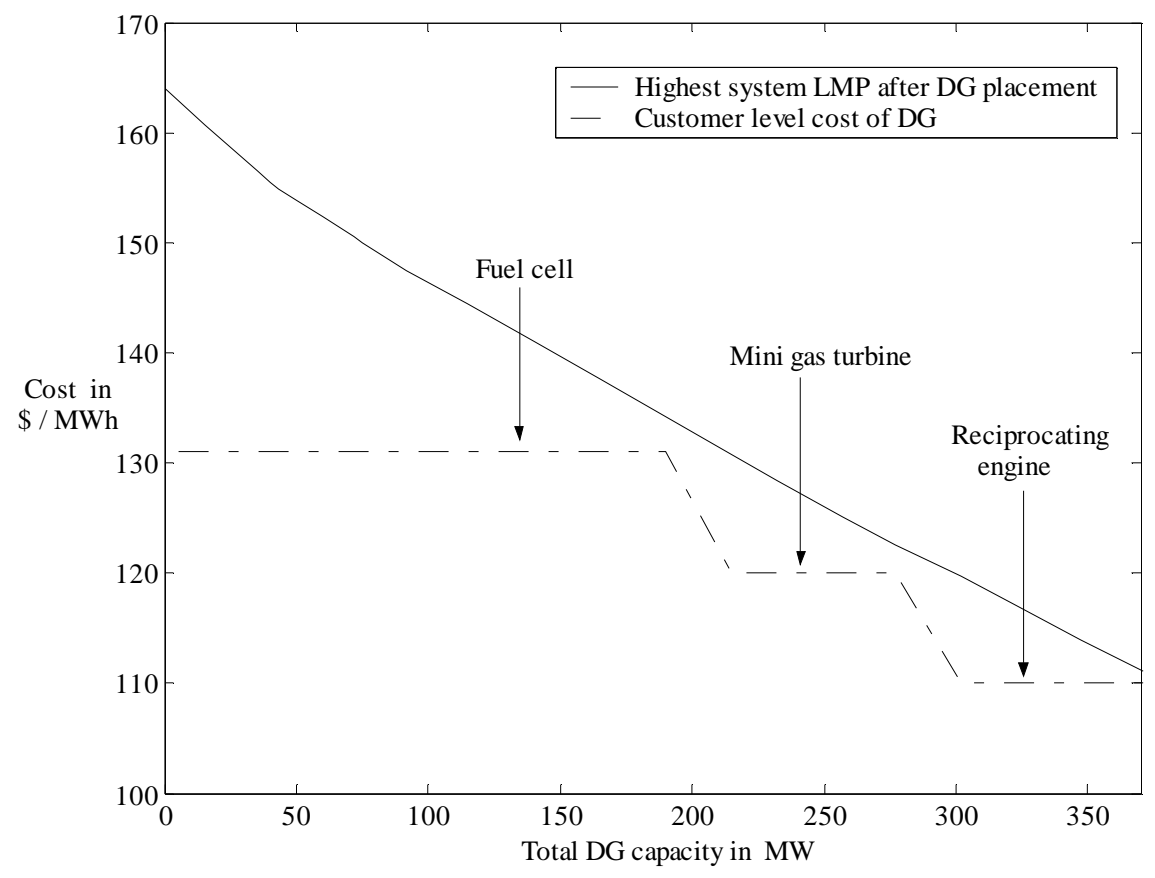

Figure 5 Impact of DG penetration on system LMP (IEEE 118 bus) 


\subsection{Effect of contingency on DG penetration}

Contingency (ies) can be line outage(s) or generator outage(s). They can even lead to congestion where, it is well known that the LMPs increase along the congested path. In this work, a single contingency case corresponding to a single generator outage is considered in the MATPOWER 30 bus system. The generator at bus number 1 is isolated from the system by tripping the lines connected to bus 1. It is observed that the system LMPs at almost all the nodes increase. It is further observed that the viability of DG increases in such a situation. Table 5 shows the comparison of LMPs under the two situations. The results indicate the utility of DG under contingency.

These studies can be extended for congestion management for which thorough contingency ranking study is essential. If the network has frequent congestions, the DG placement should take cognizance of this factor.

Table 5 Effect of contingency on LMP

\begin{tabular}{|c|c|c|c|c|c|}
\hline $\begin{array}{c}\text { Node } \\
\text { No. }\end{array}$ & $\begin{array}{c}\text { LMP without } \\
\text { contingency }\end{array}$ & $\begin{array}{c}\text { LMP with } \\
\text { contingency }\end{array}$ & $\begin{array}{c}\text { Node } \\
\text { No. }\end{array}$ & $\begin{array}{c}\text { LMP without } \\
\text { contingency }\end{array}$ & $\begin{array}{c}\text { LMP with } \\
\text { contingency }\end{array}$ \\
\hline 2 & 122.90 & 150.67 & 17 & 127.48 & 156.74 \\
\hline 3 & 123.79 & 152.17 & 18 & 128.31 & 160.03 \\
\hline 4 & 124.08 & 152.09 & 19 & 129.15 & 160.20 \\
\hline 5 & 124.16 & 151.91 & 20 & 128.76 & 159.27 \\
\hline 6 & 124.38 & 151.84 & 21 & 129.78 & 167.37 \\
\hline 7 & 125.43 & 153.18 & 22 & 120.15 & 127.19 \\
\hline 8 & 180.29 & 192.15 & 23 & 117.97 & 117.16 \\
\hline 9 & 126.15 & 154.46 & 24 & 122.04 & 127.84 \\
\hline 10 & 127.06 & 155.82 & 25 & 127.09 & 139.07 \\
\hline 11 & 126.15 & 154.46 & 26 & 129.25 & 141.40 \\
\hline 12 & 124.87 & 155.50 & 27 & 129.23 & 144.91 \\
\hline 13 & 124.87 & 155.47 & 28 & 135.74 & 158.38 \\
\hline 14 & 126.56 & 158.46 & 29 & 131.10 & 147.84 \\
\hline 15 & 125.90 & 158.52 & 30 & 133.81 & 150.57 \\
\hline 16 & 126.60 & 156.63 & \multicolumn{3}{l}{} \\
\cline { 1 - 4 } & \multicolumn{5}{r|}{}
\end{tabular}

\section{Conclusions}

In this paper, an algorithm is proposed for solving the DG placement and penetration problem. The DG is a viable solution at a node provided that cost of grid electricity is higher than the DG electricity cost. LMP is used as an indicator of grid electricity cost at a node as it is sensitive to generation cost, losses and 
Agalgaonkar et al.: Placement and Penetration of Distributed Generation under Standar

location of the node in the system. Installation of DG reduces the LMPs in the system. When LMP reduces below DG marginal cost, further addition of DG becomes economically unviable. The effect of contingencies on DG planning requires more detailed investigations and it will be the subject of future research.

\section{References}

Ackermann T., Andersson G., and Soder L., Electricity Market Regulations and their Impact on Distributed Generation, Proc. Int. Conf. Elect. Utility Deregulation Restructuring Power Technol., London, U.K: 608-613, 2000.

Alvarado F. L., Locational Aspects of Distributed Generation, Proc. IEEE Power Engineering Society Winter Meeting, Vol. 1: 140, 2001.

Brown R. E., Pan J., Feng X., and Koutlev K., Siting Distributed Generation to defer T\&D expansion, Proc. IEEE / PES Transmission and Distribution Conference and Exposition, Vol. 2: 622 - 627, 2001.

Bhowmik A., Maitra A., Halpin S. M., Schatz J. E., Determination of Allowable Penetration Levels of Distributed Generation Resources Based on Harmonic Limit Considerations, IEEE Transactions on Power Delivery, 18(2): 619-624, 2003.

Celli G. and Pilo F., Penetration Level Assessment of Distributed Generation by means of Genetic Algorithms. IEEE Proc. of Power System Conference, Clemson, SC, 2002.

Davidson I. E. and Ijumba N. M., Optimization Model for Loss Minimization in Deregulated Power Distribution Network, Proc. IEEE Africon, George, Cape: 887-894, 2002.

Engel M., Markets for Distributed Generation, Proc. IEEE Power Engineering Society Summer Meeting, Vol. 1: 52, 2000.

Khattam W. E. and Salama M. M. A., Impact of Distributed Generation on Voltage Profile in Deregulated Distribution System. Proc. of Power System Conference, Clemson, SC, 2002.

Kulkarni S. V., Khaparde S. A. and Agalgaonkar A. P., Optimal placement and penetration level assessment of Distributed Generation in MV Distribution Systems. Proc. of Power System Conference, Clemson, SC, 2003. 
Lively M., Saving California with Distributed Generation, 2001.

http://www.LivelyUtility.com

Schweppe, F. C., Caramanis M. C., and Tabors R. D., Spot Pricing of Electricity. Kluwer Academic Publishers, Boston, 1988.

Shahidehpour M., Distributed Resources for Transmission Congestion and Expansion Management, Proc. IEEE Power Engineering Society Summer Meeting, Vol. 3: 1045-1048, 2002.

Willis H. Lee and Scott W. G., Distributed Power Generation Planning and Evaluation. Marcel Dekker, Inc, New York, 2000.

Xingwang M., Sun D. I., and Cheung K. W., Evolution Toward Standardized Market Design. IEEE Transactions on Power Systems, 18(2): 460-469, 2003.

Zimmerman R. and Gan D., MATPOWER: A MATLAB Power System Simulation Package, 1997.

http://www.pserc.wisc.edu/ecow/get/publicatio/1998public/manual.pdf 